\title{
Therapy in the Age of Legalized Marijuana: A Qualitative Study of Counselors' Experience in Responding to Patient Marijuana Use
}

\author{
Darlene Walker \\ California Southern University, Costa Mesa, California, USA, \\ Casey Mace Firebaugh ${ }^{1}$ \\ Central Washington University, Ellensburg, Washington, USA \\ Gina Craft \\ University of Phoenix, USA \\ Patrick McKiernan \\ California Southern University, Costa Mesa, California, USA \\ Cynthia Palmisano \\ Saybrook University, USA
}

\begin{abstract}
A qualitative phenomenological study, the lived experiences of clinicians who treat clients using marijuana pre- and post-legalization in California are explored. This study was conducted to better understand the misconceptions associated with user attitudes and beliefs about marijuana use and provide clinicians, researchers, and physicians with information on the overall physical and emotional effects of marijuana use. Since legalization, investigating attitude and belief changes was essential to understanding the impact of marijuana's accessibility on user behaviors. Participants $(n=10)$ were licensed mental health care providers working in California who provided treatment for current or recent users of marijuana products over the last year. A 20-question open-ended interview was delivered via Zoom regarding provider experiences with client marijuana use disclosure post-legalization. A thematic analysis of qualitative data was performed. The results provide clinician insights about post-legalization marijuana attitudes and beliefs about use. Findings revealed differences in reported youth and adult-use behaviors. Reduced stigma and social acceptance of marijuana post-legislation has resulted in clients' more clearly, openly, and honestly addressing their drug use, specifically, use behaviors associated with marijuana products. There is a need for research to further explore the attitudes and beliefs of users and how often CUD is identified and treated in clinical therapy. This study has provided the perspective of the therapy provider treating individuals who use cannabis. This study provides opportunities for further study on the legalization of marijuana, potency, and accessibility of marijuana as it pertains to the practice of clinical therapy with cannabis users as legalized use continues to increase for recreational and medicinal use.
\end{abstract}

KEYWORDS: Cannabis Use Disorder, CUD, Clinical Therapy, Qualitative, Mental Health.

\footnotetext{
${ }^{1}$ Corresponding Author: A professor of public health at Central Washington University and an Associate Scientist at the Oregon Research Institute, USA. E-Mail: caseyandfiske@gmail.com
} 
Marijuana is the most consumed drug globally, with over 192 million people admitting to using cannabis and cannabis products (Miller et al., 2020). According to Stuyt (2018), after decades of propagation, marijuana has increased in potency. THC levels have risen from around two percent to between $17 \%$ and $28 \%$, based on information from dispensaries across the US. This highpotency marijuana, while legally produced and distributed, has a more significant potential to result in addiction, a consequence that is neither addressed by the legislation nor by proponents of legalized marijuana and local dispensary sales (Cash et al., 2020; Clarke, 2018; Miller et al., 2020).

Cannabis use disorder (CUD) causes clinically significant impairments due to the recurrent use of marijuana, including those associated with residual health problems, persistent or increasing use, and failure to meet primary responsibilities at work, school, or home (Connor, et al., 2020). The prevalence of marijuana use has increased for men $(+4.0 \%)$ and women $(+2.7 \%)$, with much of the uptick occurring between 2007 and 2014 (Carliner et al., 2017). In addition, there is evidence that the increases in cannabis potency, prenatal and unintentional childhood exposure, and amplified access and use by adults have led to increased CUD diagnoses, in addition to more cannabis-related emergency room visits and fatal vehicle crashes due to cannabis-associated impaired driving (Hasin, 2017).

Existing research has outlined a variety of mental health conditions exacerbated by CUD drug-induced psychosis, schizophrenia, depression, and anxiety, the link between marijuana use, mental health (Hasin, 2017). Presently, oversight of the sale of marijuana in California is monitored ineffectively, leaving things like potency, pricing, availability, consumption, i.e., personal use quantities versus commercial quantities variable (Adinoff \& Reiman, 2019; Cash et al., 2020). This lack of oversight poses a risk to vulnerable populations like young adults, socially or peer-influenced individuals, and those who are naive to the possible harms of marijuana use. Legalization and accessibility of marijuana are perceptible; however, the consequences to mental and physical health, criminal implications of use and sales, and other unforeseen side effects are not known to many of the individuals who participate in the legalized purchase and use of marijuana (Adinoff \& Reiman, 2019).

The lack of research on marijuana legalization and its impact on addiction and use over the long term puts communities at risk for behaviors and consequences associated with addiction (Bailey et al., 2020; Hines et al., 2018). In addition, the limited availability of research on the physiological, psychological, and social impact of the recent legalization of marijuana has unknown implications for treating clients in a mental health setting. The current study provides the perspective of mental health clinicians on marijuana legalization in the practice and delivery of mental health services to marijuana users that could further inform and improve patient disclosure, treatment, and outcomes.

This study aimed to answer the following research questions:

RQ1: How have therapists' attitudes towards the use of marijuana in clients changed since legalization?

RQ2: Since legalization, are clients more open and willing to disclose and discuss their marijuana use behaviors?

RQ3: Do therapists notice any patterns of use or abuse that differ between individuals who have used marijuana since adolescence versus those who uptake marijuana use at a legal age? 


\section{Methods}

A qualitative study was conducted to address the gap in knowledge around mental health clinicians experience of patient marijuana use/disclosure post-marijuana use. A descriptive phenomenological approach was employed to explore the experiences of these practitioners related to this societal and legal shift. Phenomenological research methods are useful in this context as they assist in understanding challenging social problems (Witkop, \& Varpio, 2019). As many practitioners were trained and licensed during a time when marijuana was an illicit substance, it is not clear how this changing social and legal landscape have impacted their own perceptions and practices. As each state in the US has its own approach to marijuana legalization policy and implementation, this study only targeted practitioners in the state of California.

Participant inclusion criteria consisted of being aged 18 and over, living and practicing the state of California, and having had experience with a patient disclosing marijuana use. Snowball sampling, a form of convenience sampling was used in order to gain participants. Participants were screened for eligibility and completed informed consent verbally over a passcode protected video conference call due to COVID-19 restrictions. Open-ended individual interviews were then also conducted by the first author via the passcode protected video call also due to COVID-19 protocols and recommendations by the state of California and the Centers of Disease Control.

The study instrument (Appendix A) was developed based upon a literature review of data gaps and to answer the research questions. Interviews were recorded and transcribed, and the interviewer also took notes of during the interviews. Participants were assigned ID numbers so that their data would be only identified with their ID number and not their name. The data gathered from transcription and notes were coded by hand and analyzed for reoccurring themes as described by Moustakas (1994) and the modified Van Kaam method (1966). Themes were then sorted into which research questions they answered (Busetto et al., 2020; Vass et al., 2017). Triangulation checking occurred by comparing findings of the transcripts and interview notes between members of the research team. This study was reviewed and approved by the California Southern University IRB (01/2020).

\section{Results}

\section{Theme one: Since legalization, providers need to take personal inventory and adjust their} mindsets accordingly.

The first theme to emerge was that the legalization of marijuana sales and use in California had instigated the need for a paradigm shift among the clinicians who treat addiction, SUD, and CUD. In previous research on the dangers and legalities surrounding drug-use behaviors, marijuana was consistently grouped with narcotics, and other hazardous substances (Adinoff \& Reiman, 2019; Cerdá, 2017; SAMSHA, 2019a; Volkow et al., 2016), thus clinicians were free to approach drug use behaviors as negative, dangerous, illegal, or as clinically problematic. While addiction is the primary focus of treatment and not the legal/illegal aspects of drug acquisition and use, a significant role is still played in treatment processes surrounding at-risk behaviors and behavioral consequences (Bailey et al., 2020; Hasin, 2017; Hines et al., 2018; NIDA, 2019; Stuyt, 2018).

By removing legal stigma and the overarching threat of possession/use disclosure from treatment standards, therapists must reevaluate treatment approaches and personal attitudes toward marijuana use as an alternative to other types of addiction and use behaviors. Clinical bias of any sort is discouraged and complicated, but adjusting to legal changes such as legalized marijuana 
requires clinicians to evaluate principle beliefs about drug use among their patients (Hudak, 2016; Miller et al., 2020). Changing the legal aspects of marijuana use alters, or removes, clinical approaches centered around risk behaviors, legal consequences, and significances associated with stigmatized behavior (Cash et al., 2020; Clarke, 2018; Hudak, 2016), resulting in impotent arguments and null treatment approaches surrounding use behaviors. Study participants 1, 3, 4, 6, 7, and 9 said they were not prepared for the shift in client attitudes toward marijuana use immediately after legalization, stating that client attitudes forced their adjustment to the new parameters. In a system that promotes abstinence, participant 2 stated, "Counseling a patient who struggles with CUD in this new climate is now similar to other habitual and addictive behaviors such as eating disorders. Clients' perspectives are different with legalization." Participant 5 stated, "Regardless of legal/illegal, excessive use still impacts addiction and diagnosis of CUD/SUD, but it was my attitudes about law-abiding versus law-breaking that had me adjust my approach." Participants 7, 9, and 10 each agreed their attitudes and therapeutic approaches to treatment had to be compromised to account for client use adjustments and consistent access to legal possession and use of marijuana.

\section{Theme two: Treatment approaches require updating to align with alcohol use/abuse parameters.}

The second theme emerged to supplement theme one. Participants realized at intervals that legalization shifted addiction and use behaviors among consistent users of marijuana. It initiated use behaviors among previous users of prescription pain medications and alcohol users. It redefined some markers for SUD and CUD by altering problematic consequences. Existing research on substance use difficulties and addiction set treatment guidelines for abstinence and relapse prevention (Gorelick, 2020; Henssler et al., 2019; Schmidt et al., 2016); however, newer outlooks on the treatment of drug addiction, CUD, and SUD, must be more closely aligned with alcohol use disorders since marijuana legalization in California.

Participants 2, 5, and 8 said that they had had clients who decided to disregard their CUD diagnosis after legalization, and participant 6 said explicitly, "I have had no less than 10 patients refer to marijuana use in the same context as cigarette smoking or drinking, which technically is accurate based on the law, but marijuana use seems different to me somehow. Clients had started using the law as an excuse for using marijuana, when before legalization they were working on recovery." Study participants 2, 7, and 9 recounted stories where clients had stopped CUD therapy after marijuana was legalized citing because of legalization, they no longer had a "problem." While participant 1 stated that he had had a few clients who evolved from problematic drug use behaviors before legislation, to excessive use post-legislation in what he called a "leveling off period," which he clarified, "They lost control. The fear of getting caught helped them maintain their use patterns, but the freedom of legalized marijuana set them on a path of increased use for months after the law passed. I've had to adjust my approach accordingly."

Participant experiences with client increase in marijuana use immediately post-legislation, and then tapering off as the novelty of legalization waned, were similar to studies in Colorado (Ghosh et al., 2016) where clinicians noted a paradigm shift between alcohol use and marijuana use behaviors. As a result, clinicians have had to adjust their attitudes and treatment approaches in states with lenient or legalized marijuana laws to align with client impressions of marijuana being less harmful than prior to legalization. 


\section{Theme three: Negative experiences with use behaviors are dependent upon several factors.}

Participants had differing opinions as to what constitutes a negative experience based on their perceptions and the perceptions of their clients. Existing research supports participants' scaled responses for assessing negative marijuana use experiences measured by individuals' opinions, familiarity, and judgment of use consequences (Adinoff \& Reiman, 2019; Bailey et al., 2020; Hines et al., 2018). Therapists who have never tried marijuana, have had adverse experiences with marijuana use, or have personal biases or feelings about marijuana use and users may ineffectively treat CUDs in their clients (Cerdá, 2017; Maxwell \& Mendelson, 2016). For some, negative experiences are explained as legal difficulties, including police contacts, or consequences related to "driving under the influence (DUI)" charges, while others associate negativity with family members finding out about their drug use (Smart \& Pacula, 2019; Volkow et al., 2016).

Negative experiences also include drug use on the user's health, relationships, and professional activities. Study results demonstrating personal impacts are similar to those found in other research noting the difficulties linked with addiction and frequent use of marijuana and other drugs (Bailey et al., 2020; Hasin, 2017; Hines et al., 2018; NIDA, 2019; Stuyt, 2018). Most therapists would agree that legal troubles associated with drug use, including legalized drug use, is problematic and requires addressing in a therapeutic setting.

Participants 1, 3, and 4 have had clients who have experienced negative legal repercussions that resulted in jail or prison sentences, and participants 5, 6, 7, and 9 have had clients who received probation for possession of drugs and being "under the influence." In addition, all participants have had court-mandated clients attend treatment and drug rehabilitation, which, based on existing literature, is common within substance abuse populations (Cash et al., 2020; ElSohly et al., 2016; Stuyt, 2018).

Participants 1,2,8, and 9 reported they had used marijuana as teenagers and young adults, indicating their use was limited to high school and college, peer-group influences, and "growing pains." None of this group admitted to problematic use behaviors, addiction, or legal issues surrounding acquiring, using, or possessing illegal marijuana. However, participants 4, 5, 6, and 10 stated they had used marijuana and other controlled substances, such as cocaine, methamphetamine, and ecstasy (MDMA), at various times in their lives. Participants 4, 6, and 10 each stated that their drug use led to addiction and recovery, which positively influences their treatment approaches and interactions with CUD and addicted clients.

Discussion Research Question One

Changes in stigmatized drug use behaviors have instigated a need for shifting treatment approaches. Legal difficulties were used to deter persistent marijuana use among CUD/SUD patients in clinical settings, but legalization has altered treatment for some patients. Clinicians' bias must be managed and altered when marijuana use is akin to social alcohol use behaviors. Clinicians must reevaluate their principle beliefs about marijuana use, abstinence, and moderate or social use behaviors during shifting paradigms and redefined markers for SUD and CUD. The negative experiences associated with drug/marijuana use behaviors are represented by scaled differences associated with clients' perceptions. The consequences and legal ramifications of marijuana use, possession, and acquisition have been reimagined by the legal system, and therefore, they must also be redetermined for treatment standards. 


\section{Results Research Question Two}

\section{Theme one: Legalization briefly influenced use behaviors among CUD clients, but changing legislation and societal shifts significantly affected use behaviors among newer users of marijuana products.}

The legalization of marijuana and increased potency adjustments noted in previous research are not accounted for in existing research on use behaviors; thus, problems that are directly aligned with use behaviors and legalization continue to evolve (Gorelick, 2020; Henssler et al., 2019; Sabioni \& Le Foll, 2018). Client use behaviors appear to fluctuate depending on the age of onset and the proposed reason for use initiation. Among participant clients who began using marijuana products in adolescence, use curtailed in adulthood with an average percentage estimated at 15$20 \%$ of the clients represented by participants' caseloads reinitiating marijuana use post-legislative changes, which is similar to data provided by SAMSHA (2019), and the WHO (2016).

Participants' clients who received therapy for addiction versus those whose marijuana use is recreational present differently in session. According to participants 1, 7, and 9, their CUD clients reluctantly discuss their specific acquisition and use practices, while participants $2,3,5,6$, and 7 reported their CUD clients routinely avoid discussions about their use behaviors to circumvent or delay intervention tactics (Gorelick et al., 2020; Hajihosseini et al., 2020; Kilmer, 2017). However, each of the participants agreed they had experienced clients who mention marijuana use casually as if considering legalized recreational use as similar to enjoying a glass of wine. In these instances, participants who advocate for total abstinence of any/all substances (participants 1, 2, 4, 5, 7, and 10), consider client attitudes as careless (Hajihosseini et al., 2020; Sullivan \& Austriaco, 2016), whereas the remaining participants' approaches to substance abuse management were less stringent, to the point where participants 3 and 9 agreed total abstinence is unnecessary or is dependent upon the drug or alcohol of choice, the consequences associated with use behaviors, and individual client addictive responses.

New users of marijuana products in the post-legislative environment include adolescent and adult users. Participants shared their opinions and experiences with young people whose use behaviors are being influenced and established during a time when there is signage and print advertising publicizing dispensaries without censorship (Cash et al., 2020; Clarke, 2018; De Luca et al., 2016; Miller et al., 2020). Only half of the participants treated adolescent clients, but all participants worked with families experiencing adolescent drug use. Participants 1, 4, 6, 9, and 10 stated that their young clients provide a variety of reasons for their use behaviors including, peer pressure to conform with others, stress, depression, anxiety, and to cope with parental abuse (Best et al., 2016; Lancer \& Van Horn, 2017). The family therapists provided similar accountings, including disrupted family systems, parental difficulties, including divorce, excessive hours away from the family, and financial problems that affect family-wellbeing (Naviabi et al., 2017; Wendt \& Gone, 2017).

Theme two: Clients slowly adapt to the reduced stigma associated with legally compliant use behaviors and therapeutic presentation.

Participant 7 said specifically, "Adolescents experience stigmatization automatically because of their reduced age, level of maturity, and limited decision-making capability; therefore, drug use is never condoned." According to existing research, children and adolescents who begin using drugs and alcohol in elementary and middle school react differently to stigmatized responses 
than older adolescents and young adults (Bolshakova et al., 2019; Bozinoff et al., 2018; Olfson et al., 2018; Rogers et al., 2019; Shover et al., 2019).

Participants reported that adult use had increased steadily since legalization, with participants $1,2,3,5,6,7,9$, and 10, stating they have had clients successfully substitute marijuana for opioids, especially their clients who developed addictions attempting to manage chronic pain. Other adult-use scenarios include people who used marijuana in adolescence but have abstained in adulthood and people who have chosen marijuana for use recreationally as a replacement for highly caloric alcoholic drinks (Bolshakova et al., 2019; Bozinoff et al., 2018; Olfson et al., 2018; Rogers et al., 2019; Shover et al., 2019).

Some participants shared their concerns that destigmatized drug use is detrimental to CUD outcomes. Similar to findings in other studies, participants 3, 7, 9, and 10 recalled experiences with clients who have suffered negative mental and physical outcomes due to excessive marijuana use that was instigated by relaxed views surrounding drug use behaviors (Bozinoff et al., 2018; Daniller, 2019; Lafaye et al., 2017). Ramifications included job loss, divorce, arrests for driving under the influence, and public intoxication, along with increased comorbid depression and anxiety diagnoses (Davenport \& Caulkins, 2016).

\section{Theme three: Adolescent versus adult-onset marijuana use differs significantly.}

While adaptation to legislative changes has influenced marijuana use behaviors amongst new and existing users, the adaptive process has affected groups differently. Participant responses during the interview indicated that since adolescents who use marijuana do so illegally regardless of legalization, use behaviors have fluctuated only slightly with normal instabilities noted in existing research (Blair et al., 2019; Cerda et al., 2017; Rusby et al., 2018).

Adolescents who begin using drugs and alcohol around the age of 12 are more influenced by family strife, parental neglect or addiction, and mental health problems than those who initiate use at age 15 or older above who are more peer-influenced (Adinoff \& Reiman, 2019; Cerdá, 2017; SAMSHA, 2019a).

Responses provided by participants concurred with existing research that addresses adolescent drug use behaviors, which most agree are dependent upon the same factors, including peer-pressure, peer-group influences, teen-angst, and growing pains, or in cases of early-onset, family difficulties, neglect, and mental health deficits (Di Forti et al., 2018; Gage et al., 2016; SAMSHA, 2019a). The "right of passage" associated with marijuana use by teenagers is similar to attitudes about teen-drinking behaviors (Sabioni \& Le Foll, 2018). Differences arise, however, with adult influences over adolescent behaviors (Bassir et al., 2018; Carliner et al., 2017). For example, more adults drink alcohol in front of their children than who use marijuana or other drugs openly (Bowman-Bowen \& Menard, 2016; Sullivan \& Austriaco, 2016); therefore, adolescent viewpoints toward marijuana use, regardless of legalization, remain influenced by parental attitudes (Diao \& Huestis, 2017; Rong et al., 2017).

For adults who have unwavering opinions about drugs, including marijuana, changes in legislation have had little to no effect, although according to participants 1, 2, 3, 4, 5, 8, and 10, several of their clients who are not CUD or SUD afflicted have admitted to trying marijuana for the first time since legalization citing that the legal aspects of drug use have always been a deterrent. None of the participants had experienced clients who became addicted or who developed chronic use behaviors from adult experimentation, which is supported by existing research (Bassir et al., 2018; Diao \& Huestis, 2017; Heather, 2017; Olfson et al., 2018). The adult-use behaviors of consistent adult marijuana users have increased nominally since legalization, according to 
participants 1-10 whom each had at least one client whose drug use behaviors had increased significantly due to legislative changes and the "freedom" to partake at will.

\section{Discussion Research Question Two}

The use behaviors represented by participant clients were diverse depending on the age at the time of initial use and the reason for initiating use. Adolescents and children who engage in drug use behaviors all do so under illegal conditions. Thus, use behaviors remain outside of social norms for this age group. However, initialized use among adults appears to be contingent upon past adolescent use behaviors and reasons for the onset of new use behaviors in adulthood, with marked differences between those who re-engaged in use after abstaining and those who initiated use because of legalization. Signage, advertising, and dispensary availability of marijuana products in neighborhoods have affected adolescent use stigmatization only minimally because of the reduced age at onset. In contrast, young and mid-aged adults experience fewer stigmatized responses at onset due to availability and legalization. Nonetheless, participants agreed that destigmatized use is harmful to CUD outcomes.

\section{Results for Research Question Three}

Theme one: Primary use-behavior influences are affected by the desire to lessen pain, unwind, or escape, and attitudes are most affected by stigma directed at use behaviors and legalization.

Many factors influence the use of marijuana and cannabis products. Individual use behaviors vary significantly from child and adolescent onset to adult-onset. Participants 1-10 agreed that adults who begin using marijuana later in life, or past the age of 40, initiating use is most often related to certain medical conditions, including cancer treatment, pain management, and conditions like glaucoma, inflammation, and reduced appetite (Adinoff \& Reiman, 2019; Memedovich et al., 2018; Sullivan \& Austriaco, 2016). Mental health disorders are also treated using marijuana or its derivatives, including anxiety, schizophrenia, posttraumatic stress disorder, chronic stress, and sleep disturbances (Azagba et al., 2019; Hines et al., 2018; Miller et al., 2020).

Other adults who use marijuana regularly are those addicted to substances and those diagnosed with SUD or CUD (Azagba et al., 2019; NIDA, 2020; Scocard et al., 2017). Participants' clients were substantially represented among CUD patients whose drug use behaviors were elevated past recreational use, with many experiencing polydrug use addictions (Diao \& Huestis, 2017; Fattore, 2016; Henrichson \& Delaney, 2016). Participants 4, 7, and 9 had patients who had experienced overdosing on a combination of drugs where marijuana played a part. Participants 1 , 3,8 , and 10 have patients who are significantly impaired due to what they identified as prolonged use patterns resulting in "drug burnout," which is described in research as blunting or depletion of the brain neurotransmitters that control emotional responses, perception, memory formation, and other functions like hunger and thirst management. While this condition is not permanent, continued use of drugs without affording the brain the opportunity for recuperation results in burnout that worsens and recovery from the blunted condition and emotionally dulled state diminished (Vendel et al., 2020).

The stigma associated with drug use affects adolescents and adults, and stigmatization is influenced by societal views on marijuana use regardless of legalization (Cragg et al., 2019; Lafaye et al., 2017; Rogers et al., 2019). Participants 2, 3, 5, 6, 8, and 10 had clients who have experienced problematic relationship outcomes because of clients' use behaviors, and participants 1, 4, 7, and 
9 said that clients are more stigmatized by family members than by friends resulting in emotional difficulties including feelings of being judged, failure, and abandonment (Clarke, 2018; Miller et al., 2020; Olfson et al., 2018).

Theme two: Marijuana use outcome expectancies fluctuate based on user behaviors and attitudes juxtaposed with positive and negative use outcomes.

The second theme to evolve concerned the diverse relationship between societal and personal views of drug use, legalization signifying agreement that using marijuana is legally sanctioned, and positive/negative effects of marijuana use. Participants 1, 2, 4, 5, 7, 9, and 10 stated that their clients representing ethnic minorities report more frequent contact with police than Caucasian clients. Participants described how their clients appear to get pulled over, searched, and detained more frequently for offenses similar to possession of drugs or under the influence of drugs/alcohol. Research about legalized marijuana and racial minority conflict based on user behaviors is limited; however, existing research indicates conformity with participant responses (Gorelick, 2020; Henssler et al., 2019; Sabiono \& Le Foll, 2018).

Positive and negative experiences are also subjective based on participant experiences with their CUD and marijuana user clients. Participants 1-10 each had clients who have used marijuana since adolescence without consequences, while they also had several clients who have experienced an abundance of personal, social, familial, and professional effects related to their drug use behaviors. Participants recounted that among clients who have not experienced negative side effects to their drug use, their level of denial and refusal to abstain is greater than those who have experienced adverse effects, but the recovery rate between both client types is similar. Recovery is often dependent on family support, level of addiction, drug of choice, and intervention/treatment efforts (Best et al., 2016; Gamble, 2018; Schmidt et al., 2016); thus, affected client responses are subjective to their personal and psychological conditions.

Participants 1-10 each noted that their clients had been evicted from housing, lost jobs, been arrested, been hospitalized, disowned by family, and numerous other effects, including the loss of children to adoption and foster care, and nearly dying from overdoses or at-risk behaviors while intoxicated (Griffen et al., 2020; Xu \& LaBar, 2019). While these circumstances would provoke many to change living situations, participants $1,2,4,5,6,7,9$, and 10 had clients who appeared unmoved by the aforementioned consequences. For example, participant 3 stated, "It's all about the drug. When someone is in active addiction, all circumstances are filtered through the drug, which is why it is so hard to break in and encourage recovery." Participant 7 similarly found that "The addict is in a constant state of, 'Where are the drugs, when do I get to use the drug, how can I get more drugs,' and being high. There is little room for anything else, including jobs and family in this state." As noted in the existing literature, participant experiences are similar to those of other treatment professionals who work with drug use and addicted populations (Best et al., 2016; Gorelick, 2020; Hoffman, 2016; Schmidt et al., 2016).

\section{Theme three: Recommendations for the guidance provided to adolescents or adults are similarly focused on outcome expectations of user behaviors.}

Participants each had opinions based on their extensive experiences with their clients who use marijuana and their CUD clients. The cumulative impression given by participants was that their clients are individuals who have a specific, explicit, and personal problem that is individual to their experiences and subject to their interpretations of use outcomes. Every client approaches their drug use differently. Therefore, every therapist or intervention has to be tailored to meet client 
needs, regardless if the client is an adult or child (Gerra et al., 2019; Lipari \& Van Horn, 2017; Sabioni \& Le Foll, 2018).

Cycles of addiction and use that initiate in childhood are often responses to abusive, neglectful, or other difficult circumstances (Best et al., 2016; Lancer \& Van Horn, 2017), whereas marijuana use in adolescence and young adulthood is approached as typical to growth and maturing (Bowman-Bowen \& Menard, 2016). Adults who choose to engage in marijuana use behaviors are the least likely to escalate use into addiction and CUD (Silver et al., 2020; Smart \& Pacula, 2019), while those seeking pain relief for chronic conditions, are more apt to evolve into complicated relationships with opioids and other narcotics (Hasin, 2017; Resko et al., 2019; Volkow et al., 2016; Zvonarev et al., 2019).

Participants 1-10 have clients who fit into each of the described categories, and participants 1 and 9 treat families where parents and their children who range in age from 11 to 18 are all using marijuana, alcohol, and other drugs. Participants agreed that early intervention is essential to treatment and sobriety outcomes and that support outside of the therapeutic environment is key to client success and failure. Participant 6 stated, "Parents and families are so busy and scheduled, finding opportunities to engage them in therapy when their kids are declining is difficult. So many parents are either in denial, or they just don't understand how bad it can get when an adolescent starts using drugs." "The big question is why," participant 2 said. "Why did/does the child feel the need to alter their consciousness with drugs; why is it better than their reality?" Participant comments/questions applied to their adult clients as well; in similar statements, participants 4 and 5 each found that adults who engage in marijuana use behaviors after adolescence experience deficits in functioning responsibly for significant periods. Existing literature is somewhat contradictory to this study's results based on data provided by Rusby et al. (2018) and Wendt and Gone (2017), who found that adult and adolescent addictive and abusive marijuana use behaviors are dissimilar but relative.

\section{Discussion Research Question Three}

Marijuana use factors differ based on the age of onset. Adults who begin marijuana use later in life do so for reasons separate from adolescent use onset. Adults who initiate use after age 40 usually associate marijuana use with medical conditions. Adults over 40 experience more cancers, arthritis, pain, and inflammation than younger people, who often initiate use for escapism and pleasure-seeking. Regular, unmanaged use behaviors can lead to SUD or CUD diagnoses regardless of age at onset or the reasons for engaging in marijuana use. Subjectivity is strongly associated with positive and negative use behavior experiences, with many participant clients experiencing and range from problematic effects to no substance use consequences. Adverse outcomes result in personal, social, familial, and professional difficulties when use behaviors exceed social levels. Mental health professionals must vary their approach to substance abuse treatment based on individual client needs regardless of age. Abuse and addiction cycles in childhood respond to difficult circumstances, whereas adult social use behaviors are less often associated with an escalation to addiction.

\section{Section Summary}

Among the topics discussed throughout participant interviews, substance abuse, marijuana use behaviors, and the significance of legalized sales of marijuana in California remains somewhat ambivalent. Participants were each aware of the effects of marijuana use on their clients, and each agreed that therapeutic interventions in user-behavior scenarios are a specialized field that not all 
therapists are prepared to navigate successfully. While some participants are themselves in recovery, they agreed that experiencing addiction provides them with insights they would not have. Otherwise, it should not be a prerequisite to providing treatment. Legalized marijuana has affected use behaviors among California residents, but adolescent use behaviors appear to be stable since the legislation did not affect them directly because to purchase or possess cannabis legally, one must be 18. Though it is noted that increased signage and marijuana sales dispensaries might influence young or impending users of marijuana products, research in this area is still evolving.

More adults have initiated marijuana use post-legislation due to reduced stigma, increased access, and negated fear of negative legal repercussions. Adults who seek to manage pain and other medical conditions are among the new users of marijuana, including those who enjoyed using marijuana in adolescence but eliminated use in adulthood. Adults who have substituted marijuana use for alcohol use or use of other medications have increased, and use is validated by medical professionals who encourage patients to use marijuana products to relieve stress, improve appetite, especially among the elderly and cancer patients, and to improve sleep.

\section{Discussion}

Study findings were established by applying thematic analysis to the gathered interview data. The themes and subthemes were developed by categorizing participant responses based on their similarities or differences. The study's theoretical framework and research questions were used to evaluate participants' feedback and associate interviews with the research presented in the literature review. The themes that were developed were sufficient to contribute to study findings.

The original limitations and delimitations outlined in this research included the possibility of researcher bias, which was mitigated by accurate reporting of participant responses and the inclusion of quoted material. Findings could have been impacted by the chosen method and study design of qualitative phenomenology, but instead of hindering results and findings, the chosen methodology served as the perfect tool to gain access to the perspectives and lived experiences of the participants and their clients. Another potential limitation was COVID-19 protocols, which were mitigated by the use of the Zoom videoconferencing platform. Each participant was relaxed and comfortable in their setting, which served the study's purpose and data gathering. Sample size, transferability, and study outcomes were all possible limiting factors. The sample size of 10 participants was ideal for data gathering and response saturation, and results should be transferrable to other states or jurisdictions where marijuana use is legally sanctioned or processes are pending.

\section{Research Question One}

Research question one was designed to understand better individual participants' attitudes toward the use of marijuana by their clients since legalization. Participants were asked questions to establish how their experiences with clients affected their perceptions of marijuana use behaviors in a post-legalization society. In addition, participants discussed their management of personal biases associated with drug use and with legislative changes relating to the effects on addiction and CUD diagnoses.

Findings from this direction of questioning indicated that participants experience several categorizations of use behaviors that range from recreational, weekend users of marijuana products to those identified with addictions and SUD or CUD diagnoses. Attitudes varied among participants and appeared to be dependent upon each participants' perspectives and drug use history. Findings fluctuated between participants with no account of previous substance abuse and those with a significant substance abuse history. Contradictory responses led to discovering that casual 
marijuana use, similar to social drinking behaviors, is tolerated by therapists who are not in recovery more than those in recovery, even when allowing for non-user bias adjustment post legislation (Cerdá, 2017; Maxwell \& Mendelson, 2016).

The impact on therapist/counselor approaches to treatment are motivated attitudes that vacillate between complete abstention, occasional consumption allowances, and client relapse prevention strategies. In addition, the paradigm shift initiated by legalization caused providers to adjust notions about use behaviors among their clients. The implication is that if the therapist would not address the clients' having an occasional alcoholic beverage-providing they are not an alcoholic, addressing occasional marijuana use is inappropriate or should be viewed in the same manner; dangerous and illegal drug use behaviors that are associated with CUD/SUD notwithstanding (Adinoff \& Reiman, 2019; Cerdá, 2017; SAMSHA, 2019a; Volkow et al., 2016).

The inconsistencies noted among participants' responses during this line of questioning indicated possible incongruities in their therapeutic approaches. Before legalization, there were clear lines of demarcation; legal versus illegal. Clinicians could consider substance use behaviors as adverse, hazardous, unlawful, and clinically significant; however, the lines are now blurred by legislation sanctioning marijuana use that has resulted in changes to client use behaviors (Bailey et al., 2020; Hasin, 2017; Hines et al., 2018; NIDA, 2019; Stuyt, 2018).

Biases that support recreational marijuana use differ from those denouncing substance use altogether, instigating theoretical adjustments to clinical approaches. Clinicians have been required to adjust their attitudes about drug use among their patients (Hudak, 2016; Miller et al., 2020) to align with legislative changes regardless of which side of the argument for or against marijuana use is supported by the therapists' personal beliefs. Modified legalities regarding marijuana use influence clinical approaches traditionally grounded in use-risk behaviors, official consequences, and impacts linked to stigma (Cash et al., 2020; Clarke, 2018; Hudak, 2016).

While the data did not provide a direct relationship with divided participant responses and treatment outcomes, it can be speculated that based on participants' personal experiences with drug use compared to those who abstain influences therapeutic approaches to treatment. While data indicates that participants were not prepared for client attitude changes and the adjustments associated with legalization, study findings imply that altering therapeutic approaches to align with new mindsets could result in successful interventions (Smart \& Pacula, 2019; Volkow et al., 2016). It can also be speculated that clinicians' approaches are influenced by personal bias. Thus, if, how, and when clinician bias is exhibited, successful intervention strategies are either supplemented or mitigated.

\section{Research Question Two}

Since the legalization of marijuana use, sales, and cultivation, participants have noticed improved disclosure of marijuana use behaviors in therapy sessions. Legalization influenced use behaviors among participant clients diagnosed with CUD briefly, but findings centered around participants' clients who are new users of marijuana products were more significantly represented. While consistent users saw an uptick in consumption for several months after legalization, frequency returned to pre-legalized use once the novelty of lawfully purchasing and using marijuana declined. New users, however, remain influenced by legalization long after the uniqueness of freely using marijuana waned, with use patterns continuing to evolve. Findings indicate that enhanced potency, availability, and inexperienced use behaviors result in increased diagnoses of CUD among young and new users of marijuana and its derivatives (Cash et al., 2020; Clarke, 2018; De Luca et al., 2016; Miller et al., 2020). 
Findings are consistent with other research, indicating that regardless of client use behavior disclosure, intervention strategies are either failing outright, or the approach to change needs modification (Gorelick, 2020; Henssler et al., 2019; Sabioni \& Le Foll, 2018). Outcomes revealed that responsible use of marijuana by some participants' clients and continued or new user behaviors is dependent on several factors, including the age at the time of onset and clients' reasons for using marijuana, e.g., recreational, escapism, addiction. Consistencies with research are also established by using behaviors developed in adolescence, restricted in adulthood, then resurfaced recreationally after legalization among $15-20 \%$ of participants' clients (SAMSHA, 2019; WHO, 2016).

Additional findings include clients with diagnosed CUD, or those who exhibited significant use behaviors before legalization, are negatively unaffected by legalization and continue to guard against disclosing use patterns, resulting in ineffective intervention. Post-legislative users, however, disclose appropriate use of marijuana and only become guarded when they perceive their use has become problematic. These findings indicate that the social stigma associated with drug use affects prolonged use behaviors but does not similarly influence developing use behaviors. Before legalization, stigmatized drug use included the covert acquisition of marijuana, legal ramifications, and ostracization (Bozinoff et al., 2018; Geider-Ornetco \& Simkings, 2018; Lafaye et al., 2018).

The reduced social stigma was apparent based on the data collected; however, differences in interpreting the data could lead to assumptions that legalization is consistent with the positive behavioral association, or legalization is the equivalent to supporting use behavior. For the participant clients represented in this study, substance abuse was already problematic in most instances. Use behaviors represented by the general population may differ from those of an addicted individual or habitual user of marijuana. If extended, the research findings can be used to make assumptions about future use behaviors beyond the findings from this group of participants involved in treating CUD and SUD patients.

\section{Research Question Three}

Additional findings imply that marijuana users' motivations influence primary use and behavioral impacts. Among the over 1000 clients in the participant interviews, use intentionality ranged from pain management, relaxation, escapism, and the desire to alter consciousness through substance use. In addition, child/adolescent behaviors differ from adult-onset use behaviors in the post-legalization era as older adults take up marijuana use to eliminate dependence on prescription medications for pain, cancer, glaucoma, and inflammation treatment, or to stimulate appetite in patients (Adinoff \& Reiman, 2019; Memedovich et al., 2018; Sullivan \& Austriaco, 2016).

Use patterns among adolescent users of marijuana have fluctuated, but only minimally. Legalized marijuana sales are based on clientele at least 21 years old; therefore, marijuana sales/purchases and use continue to be prohibited within the same legal parameters as alcohol use and sales. Research findings did reveal that one of the indicators of increased use among adolescents revolves around adult-use behaviors since legalization. In some instances, adolescents are exposed to the drug's use by parents who are using marijuana recreationally, in some cases, in place of alcohol consumption. Some participants stated their clients were exposed to alcohol abuse and drug use by their parents, while others were exposed in peer-group interactions. Clear indications were absent as to which form of exposure is more likely to result in problematic drug or alcohol abuse moving forward; however, research contends early influences related to substance abuse lead to long-term difficulties (Bailey et al., 2020; Banys, 2016; Lloyd \& Brook, 2019). 
Findings are also relevant for individuals suffering from mental health disorders who may be prescribed marijuana to manage conditions including PTSD, stress, schizophrenia, sleep disturbances, and anxiety (Azagba et al., 2019; Hines et al., 2018; Miller et al., 2020). Legalization and destigmatized use of marijuana in mainstream settings are beneficial to people who before legislation did not have access to marijuana products. With more adults turning to marijuana as an herbal remedy for various conditions and maladies, this research helps to give individuals who were previously averted to the possibilities provided by marijuana use the opportunity to understand and explore the various means available, including tinctures and edible products (De Luca et al., 2016; Jin, 2020; Rong et al., 2017).

The differences between adult and adolescent use behaviors are understood based on several factors outlined in the research findings. It can be surmised from these findings that use behaviors are influenced by the reasons for use and the age of onset. However, further speculation about instigating use behaviors among adolescent and adult users of marijuana products versus the uptake of use behaviors at intervals throughout life can be assumed to be consistent with the use behaviors outlined in the study's findings. Legalized use of marijuana in California has led to increased advertising and accessibility for adult users, but few changes for adolescents who attempt to secure legalized marijuana. Increases in adolescent use continue to evolve, but it can be presumed that adolescent use will increase over time due to accessibility.

\section{Conclusions}

The purpose of this study was to discover the impact of marijuana legalization, advertising, and access on the use behaviors of Californians. Mental health providers have experienced changes in their attitudes about marijuana use, with results varying dependent upon personal use/abstinence approaches to sobriety. Legalization was the catalyst for a paradigm shift amongst clinicians who treat CUD/SUD. Legislative and cultural changes resulting from legalized sales and use of cannabis and its derivatives diminished stigma and sanctioned use for some participants' clients who only abstained for legal and social reasons.

Clinicians reported a disregard of CUD/SUD diagnosis by their clients after legalization, resulting in perceived treatment dropout rates increasing, while others experienced elevated use behaviors that settled back into pre-legislation patterns after time. Treatment approaches centered on risk, legalities, and stigma have to be reimagined by clinicians in instances where marijuana use is recreational and not problematic. Since addiction is usually the focus of therapy with CUD and SUD clients, clinical approaches to less significant drug use behaviors require modification to include legalized consumption of marijuana products. Clinicians' perspectives must consider legalized, recreational use behaviors in the same manner as they would a non-alcohol-addicted client having a beer or glass of wine (Bailey et al., 2020; Hasin, 2017; Hines et al., 2018; NIDA, 2019; Stuyt, 2018).

Removing legal stigma from use behaviors has resulted in an increased uptake of marijuana use by individuals who refrained from use for various reasons, including legal ramifications, maturing attitudes toward use, and difficulty accessing products. For example, dispensary sales account for a considerable change in use behaviors among middle-aged and maturing adults who abstained from marijuana use after adolescence or early adulthood. In addition, increased sales and use of marijuana products are noted among individuals seeking pain management alternatives, noncaloric relaxation opportunities, and those who enjoyed the effects of marijuana but gave it up when progressing through life's intervals where professional endeavors, marriage, and childbearing/rearing became significant. 
Participant experiences with their clients did not significantly represent negative experiences associated with drug use behaviors specific to marijuana; however, challenging consequences are experienced by those clients who engage in problematic drug-use behaviors regardless of legislative changes or restrictions to access. Study conclusions represent a more straightforward path to recovery for many who experience adverse outcomes due to new or existing marijuana use behaviors. Reduced stigma and social acceptance of marijuana post-legislation have resulted in clients' more clearly, openly, and honestly addressing their drug use, specifically, use behaviors associated with marijuana products. Clients who disclose

This research, along with other studies, has the potential to elevate mental health professionals' understanding of post-legislative attitudes toward marijuana use. Clinicians who are instrumental in providing services to the addicted population and others who may indulge in recreational use behaviors are affected by legalization through changes in their clients' attitudes and behaviors. Specific awareness of attitude adjustment among providers is significant to treatment outcomes for their clients. For example, clinicians who are in recovery often advocate for abstinence, while others' approaches may differ. These conclusions shed light on the influence of provider experiences on client results, which might further understand the paradigm shift associated with marijuana use behaviors in a post-legalized society.

This study has shown that the implications for legalization of marijuana are still greatly unknown, particularly in the practice of therapy with clients who use legal marijuana products. For clinicians it is important to understand not only marijuana behavior and use, but also patterns in client disclosure. For example, adolescent users may have a different perception about disclosure rather than a client with a terminal illness or in old age. Given that there are no guidelines for "healthy marijuana use" from any health agency, medical organization, or from a professional mental health association, clinicians may feel they are mostly on their own interpreting the impact of legal marijuana use on their clients. Although there are other drug treatment approaches that could be applied, marijuana in and of itself is a unique substance with unique social and cultural patterns as well as clinical implications. Further studies should example population subgroups of marijuana users more specifically. In addition, additional training may be needed to be provided for clinicians to address a more streamlined approach for addressing cannabis using clients.

\section{References}

Adinoff, B. \& Reiman, A. (2019). Implementing social justice in the transition from illicit to legal cannabis. The American Journal of Drug and Alcohol Abuse, 45 (6),673688, https://doi:10.1080/00952990.2019.1674862.

Azagba, S., Shan, L., Manzione, L., Qeadan, F., \& Wolfson, M. (2019). Trends in opioid misuse among marijuana users and non-users in the US from 2007-2017. International Journal of Environmental Research and Public Health, 16(22), 45-85. https://doi.org/10.3390/ijerph16224585.

Bailey, J. A., Epstein, M., Roscoe, J. N., Oesterle, S., Kosterman, R., \& Hill, K. G. (2020). Marijuana legalization and youth marijuana, alcohol, and cigarette use and norms. American Journal of Preventive Medicine, 59(3), 309-316. https://doi.org/10.1016/j.amepre.2020.04.008.

Bandura, A. (1977). Self-efficiency: Toward a unifying theory of behavioral change. Psychological Review, 84(2), 191-215. https://doi.org/10.1037/0033-295X.84.2.191

Bandura, A. (1986). Social foundations of thought and action: A social cognitive theory. PrenticeHall. 
Bandura, A. (2001). Social cognitive theory of mass communication. Media Psychology, 3(3), 265-299. https://doi.org/10.1207/s1532785xmep0303_03.

Bandura, A. (2011). The social and policy impact of social cognitive theory. Guilford Press.

Banys, P. (2016). Mitigation of marijuana-related legal harms to youth in California. Journal of Psychoactive Drugs, 48(1), 11-20. https://doi.org/10.1080/02791072.2015.1126770.

Bassir, N. A., Mann, C., Kaur, H., \& Ranganathan, M. (2018). Cannabis use: Neurobiological, behavioral, and sex/gender considerations. Current Behavioral Neuroscience Reports, 5(4), 271-280. https://doi.org/10.1007/s40473-018-0167-4.

Best, D., Beckwith, M., Haslem, C., Jetten, J., Mawson, E., \& Lubman, D. (2016). Overcoming alcohol and other drug addiction as a process of social identity transition. Addiction Research \& Theory, 24(2), 111-123. https://doi.org/10.3109/16066359.2015.1075980.

Blair, R. J. R., White, S. F., Tyler, P. M., Johnson, K., Lukoff, J. Thornton, L. C., Leiker, E. K., Filbey, F., Dobbertin, M. \& Blair, K. S. (2019). Threat responsiveness as a function of cannabis and alcohol use disorder severity. Journal of Child and Adolescent Psychopharmacology, 29(7), 526-534. https://doi.org/10.1089/cap.2019.0004.

Bolshakova, M., Bluthenthal, R., \& Sussman, S. (2019). Opioid use and misuse: Health impact, prevalence, correlates, and interventions. Psychology \& Health, 34(9), 1105-1139. https://doi.org/10.1080/08870446.2019.1622013.

Bowman-Bowen, L. C., \& Menard, S. (2016). Survey design elements as influences on estimates of self-reported illicit substance use and other illegal activities. Journal of Drug Issues, 46(3), 178-197. https://doi.org/10.1177/0022042616629513.

Bozinoff, N., Anderson, B. J., Bailey, G. L., \& Stein, M. D. (2018). Correlates of stigma severity among persons seeking opioid detoxification. Journal of Addiction Medicine, 12(1), 1923. https://doi.org/10.1097/ADM.0000000000000355.

Braun, V., \& Clarke, V. (2019). To saturate or not to saturate? Questioning data saturation as a useful concept for thematic analysis and sample-size rationales. Qualitative Research in Sport, Exercise and Health. 13(2), 201-216. https://doi.org/10.1080/2159676X.2019.1704846.

Busetto, L., Wick, W., \& Gumbinger, C. (2020). How to use and assess qualitative research methods. Neurological Research and Practice, 2(14), 1-11. https://doi.org/10.1186/s42466- 020-00059-z.

Carliner, H., Mauro, P. M., Brown, Q. L., Shmulewitz, D., Rahim-Juwel, R., Sarvet, A. L., Wall, M. M., Martins, S. S., Carliner, G., \& Hasin, D. S. (2017). The widening gender gap in marijuana use prevalence in the US during a period of economic change, 2002-2014. Drug and Alcohol Dependence, (170), 51-58. https://doi.org/10.1016/j.drugalcdep.2016.10.042

Cash, M. C., Cunnane, K., Fan, C., \& Romero-Sandoval, E. A. (2020). Mapping cannabis potency in medical and recreational programs in the United States. PLoS ONE 15(3), 627636. https://doi.org/10.1371/journal.pone.0230167.

Cerdá, M., Wall, M., Feng, T., Keyes, K. M., Sarvet, A., Schulenberg, J., O'Malley, P. M., Pacula, R. L., Galea, S. G., \& Hasin, D. S. (2017). Association of state recreational marijuana laws with adolescent marijuana use. Journal of the American Medical Association, Pediatrics, 171(2), 142. https://doi.org/10.1001/jamapediatrics.2016.3624.

Clarke, P., Dodge, T., \& Stock, M. L. (2018). The impact of recreational marijuana legislation in Washington, DC on marijuana use cognitions. Substance Use \& Misuse, 53(13), $2165-$ 2173. https://doi.org/10.1080/10826084.2018.1461226.

Connor, J. P., Stjepanović, D., Le Foll, B., Hoch, E., Budney, A. J., \& Hall, W. D. (2021). Cannabis use and cannabis use disorder. Nature Reviews Disease Primers, 7(1), 1-24. 
Cragg, A., Hau, J. P., Woo, S. A., Kitchen, S. A., Liu, C., Doyle-Waters, M. M., \& Hohl, C. M. (2019). Risk factors for misuse of prescribed opioids: A systematic review and metaanalysis. Annals of Emergency Medicine, 74, 634-646. https://doi:10.1016/j.annemergmed.2019.04.019.

Creswell, J. W. and Poth, C. N. (2018) Qualitative inquiry and research design choosing among five approaches. 4th Edition, SAGE.

Creswell, J. W., \& Creswell, J. D. (2018). Research design: Qualitative, quantitative, and mixed methods approaches. Fifth edition. SAGE.

Daniller, A. (2019). Two-thirds of Americans support marijuana legalization. https://www.pewresearch.org/fact-tank/2019/11/14/americans-support-marijuanalegalization/.

Davenport, S., \& Caulkins, J. (2016). Evolution of the United States marijuana market in the decade of liberalization before full legalization. Journal of Drug Issues, 46, 411 - 427. https://doi.org/10.1177/0022042616659759.

Davis, T. L. (2013). A Qualitative Study of the Effects of Employee Retention on the Organization. ProQuest LLC. 110-130.

De Luca, M. A., Castelli, M. P., Loi, B., Porcu, A., Martorelli, M., Miliano, C., Kellett, K., Davidson, C., Stair, J. L., Schifano, F., \& Di Chiara, G. (2016). Native CB1 receptor affinity, intrinsic activity and accumbens shell dopamine stimulant properties of thirdgeneration SPICE/K2 cannabinoids: BB-22, 5F-PB-22, 5F-AKB-48 and STS-135. Neuropharmacology, 105, 630-638. https://doi.org/10.1016/j.neuropharm.2015.11.017.

Di Forti, M., Quattrone, D., Freeman, T. P., Tripoli, G., Gayer-Anderson, C., Quigley, H., Rodriguez, V., Jongsma, H. E., Ferraro, L., La Cascia, C., La Barbera, D., Tarricone, I., Berardi, D., Szöke, A., Arango, C., Tortelli, A., Velthorst, E., Bernardo, M., Del-Ben, C. M., Menezes, P. R., ... EU-GEI WP2 Group (2019). The contribution of cannabis use to variation in the incidence of psychotic disorder across Europe (EU-GEI): a multicentre case-control study. Psychiatry, 6(5), 427-436. https://doi.org/10.1016/S22150366(19)30048-3.

Diao, X., \& Huestis, M. A. (2017). Approaches, challenges, and advances in metabolism of new synthetic cannabinoids and identification of optimal urinary marker metabolites. Clinical Pharmacology and Therapeutics 101(2), 239-253. https://doi:10.1002/cpt.534 .

ElSohly, M. A., Mehmedic, Z., Foster, S., Gon, C., Chandra, S., \& Church, J. C. (2016). Changes in cannabis potency over the last 2 decades (1995-2014): Analysis of current data in the $\begin{array}{llll}\text { United States. Biological } & \text { Psychiatry, }\end{array}$ https://doi.org/10.1016/j.biopsych.2016.01.004.

Fattore L. (2016). Synthetic cannabinoids - further evidence supporting the relationship between cannabinoids and psychosis. Biological Psychiatry 79(7), 539-548. https://doi: 10.1016/j.biopsych.2016.02.001.

Feng, B. (2017). Marijuana legalization and interest in marijuana: Evidence from google trends. Social Science Research Network: Electronic Journal. https://doi.org/10.2139/ssrn.3053263.

Gage S., Hickman, M., \& Zammit S. (2016). Association between cannabis and psychosis: Epidemiologic evidence. Biological Psychiatry, 79(7), 549-556. https://doi.org/10.1016/j.biopsych.2015.08.001.

Gamble, J. (2018). Menace II society: A social learning perspective. The Graduate Review, (3), 24-37. http://vc.bridgew.edu/grad_rev/vol3/iss1/8.

Gerra, M. C., Manfredini, M., Cortese, E., Antonioni, M. C., Leonardi, C., Magnelli, F., Somaini, L., Jayanthi, S., Cadet, J. L., \& Donnini, C. (2019). Genetic and environmental risk factors 
for cannabis use: Preliminary results for the role of parental care perception. Substance Use \& Misuse, 54(4), 670-680. https://doi: 10.1080/10826084.2018.1531430.

Ghosh, T., Van Dyke, M., Maffey, A., Whitley, E., Gillim-Ross, L., \& Wolk, L. (2016). The public health framework of legalized marijuana in Colorado. American Journal of Public Health, 106(1), 21-27. https://doi.org/10.2105/ajph.2015.302875.

Gorelick, D. A., Saxon, A. J., \& Friedman, M. (2020). Cannabis withdrawal: Epidemiology, pathogenesis, clinical manifestations, course, assessment, and diagnosis. https://www.uptodate.org/contents/cannabis-withdrawal-epidemiology-pathogenesisclinical-manifestations-course-assessment-and-diagnosis.

Hajihosseini, M., Norozi, E., Azimi, T., \& Ahmadinia, H. (2020). Comparison of artificial neural networks and logistic regression for determination of social-cognitive factors impacting drug abstinence. Journal of Substance Use 25(3), 295-300. https://doi.org/10.1080/14659891.2017.1394382.

Hasin, D. S. (2017). US epidemiology of cannabis use and associated problems. Neuropsychopharmacology, 43(1), 195-212. https://doi.org/10.1038/npp.2017.198.

Heather, N. (2017). Q: Is addiction a brain disease or a moral failing? A: Neither. Neuroethics, 10(1), 115-124. https://doi:10.1007/s12152-016-9289-0.

Henrichson, C., \& Delaney, R. (2016). The price of prisons what incarceration costs taxpayers. https://shnny.org/uploads/Price-of-Prisons.pdf.

Henssler, J., Heinz, A., Brandt, L., \& Bschor, T. (2019). Antidepressant withdrawal and rebound phenomena. Deutsches Arzteblatt International, 116(20), 355-361. https://doi.org/10.3238/arztebl.2019.0355.

Hines, L. A., Morley, K. I., Rijsdijk, F., Strang, J., Agrawal, A., Nelson, E. C., Statham, D., Martin, N., \& Lynskey, M. T. (2018). Overlap of heritable influences between cannabis use disorder, frequency of use and opportunity to use cannabis: Trivariate twin modelling and implications for genetic design. Psychological Medicine, 1-8. 188-197. https://doi:10.1017/S0033291718000478.

Hudak, J. (2016). Marijuana: A short history. Washington, DC: Brookings Institution Press.

Jin, J. (2020). Screening for unhealthy drug use in adults and adolescents. The Journal of the American Medical Association, 323(22), 2350. https://doi.org/10.1001/jama.2020.8192.

Kilmer, B. (2017). Recreational cannabis: Minimizing the health risks from legalization. New England Journal of Medicine, 376(8), 705-707. https://doi.org/10.1056/nejmp1614783.

Lafaye, G., Karila, L., Blecha, L., \& Benyamina, A. (2017). Cannabis, cannabinoids, and health. Dialogues in Clinical Neuroscience, 19(3), 309-316. https://doi.org/10.31887/DCNS.2017.19.3/glafaye.

Lancer, D. (2018). Are you an enabler? Psychology Central. https://psychcentral.com/lib/are-youan-enabler/.

Lipari, R. N., \& Van Horn, S.L. (2017). Children living with parents who have a substance use disorder. In: The CBHSQ Report. Rockville (MD): Substance Abuse and Mental Health Services Administration (US). PMID: 29144715.

Lloyd, M. H., \& Brook, J. (2019). Drug testing in child welfare: A systematic review. Children and Youth Services Review, 104(389). https://doi.org/10.1016/j.childyouth.2019.104389.

Lowe, D., Sasiadek, J. D., Coles, A. S., \& George, T. P. (2019). Cannabis and mental illness: A review. European Archives of Psychiatry and Clinical Neuroscience, 269(1), 107-120. https://doi.org/10.1007/s00406-018-0970-7.

Maxwell, J. C., \& Mendelson, B. (2016). What do we know now about the impact of the laws related to marijuana? Journal of Addiction Medicine, 10(1), 3-12. https://doi.org/10.1097/adm.0000000000000188. 
Memedovich, K. A., Dowsett, L. E., Spackman, E., Noseworthy, T., \& Clement, F. (2018). The adverse health effects and harms related to marijuana use: An overview review. Canadian Medical Association Journal Open, 6(3), 13-29. https://doi.org/10.9778/cmajo.20180023.

Miller, N. S., Ipeku, R., \& Oberbarnscheidt, T. (2020). A review of cases of marijuana and violence. International Journal of Environmental Research and Public Health, 17(5), 1578-1590. https://doi.org/10.3390/ijerph17051578.

National Institute on Drug Abuse (2019). Marijuana. http://www.drugabuse.gov.http://drugabuse.gov/publications/drugfacts/marijuana.

National Institute on Drug Abuse (2020). Drug Misuse and Addiction. https://www.drugabuse.gov/publications/drugs-brains-behavior-science-addiction/drugmisuse-addiction.

Olfson, M., Wall, M. M., Liu, S. M., \& Blanco, C. (2018). Cannabis use and risk of prescription opioid use disorder in the United States. American Journal of Psychiatry, 175(1), 47-53. https://doi:10.1176/appi.ajp.2017.17040413.

Resko, S., Ellis, J., Early, T.J., Szechy, K.A., Rodriguez, B., \& Agius, E. (2019). Understanding public attitudes toward cannabis legalization: Qualitative findings from a statewide $\begin{array}{llll}\text { survey. Substance } \quad \text { Use } & \text { Misuse } & \text { 54(8), }\end{array}$ https://doi:10.1080/10826084.2018.1543327.

Rogers, A. H., Bakhshaie, J., Buckner, J., Orr, M. F., Paulus, D. J., Ditre, J. W., \& Zvolensky, M. J. (2019). Opioid and cannabis co-use among adults with chronic pain: Relations to substance misuse, mental health, and pain experience. Journal of Addiction Medicine, 13(4), 287-294. https://doi: 10.1097/ADM.0000000000000493.

Rong, C., Lee, Y., Carmona, N. E., Cha, D. S., Ragguett, R. M., Rosenblat, J. D., Mansur, R. B., Ho, R. C., \& McIntyre, R. S. (2017). Cannabidiol in medical marijuana: Research vistas and potential opportunities. Pharmacological Research, 121, 213-218. https://doi.org/10.1016/j.phrs.2017.05.005.

Rusby, J. C., Westling, E., Crowley, R., \& Light, J. M. (2018). Legalization of recreational marijuana and community sales policy in Oregon: Impact on adolescent willingness and intent to use, parent use, and adolescent use. Psychology of Addictive Behaviors: Journal of the Society of Psychologists in Addictive Behaviors, 32(1), 84-92. https://doi.org/10.1037/adb0000327.

Sabioni, P., \& Le Foll, B. (2018). Psychosocial and pharmacological interventions for the treatment of cannabis use disorder. Educational Researcher (7)1 173-180. https://doi.org/10.12688/f1000research.11191.1.

Schmidt, L. A., Jacobs, L. M., \& Spetz, J., (2016). Young people's more permissive views about marijuana: Local impact of state laws or national trend? American Journal of Public Health, 106(8), 1498-1503. https://doi.org/10.2105/AJPH.2016.303153.

Schneider, N. C., Coates, W. C., \& Yarris, L. M. (2017). Taking your qualitative research to the next level: A guide for the medical educator. AEM Education and Training, 1(4), 368-378. https://doi.org/10.1002/aet2.10065.

Shover, C.L., Davis, C.S., Gordon, S.C., \& Humphreys, K. (2019). Association between medical cannabis laws and opioid overdose mortality has reversed over time. Proceedings of the National Academy of Sciences (116), 12624-12626. doi: 10.1073/pnas.1903434116.

Silver, L. D., Naprawa, A. Z., \& Padon, A. A. (2020). Assessment of incorporation of lessons from tobacco control in city and county laws regulating legal marijuana in California. The Journal of the American Medical Association, 3(6), 111-132. e208393. https://doi.org/10.1001/jamanetworkopen.2020.8393. 
Smart, R., \& Pacula, R. L. (2019). Early evidence of the impact of cannabis legalization on cannabis use, cannabis use disorder, and the use of other substances: Findings from state policy evaluations. The American Journal of Drug and Alcohol Abuse, 45(6), 644663. https://doi.org/10.1080/00952990.2019.1669626.

Stuyt, E. (2018). The problem with the current high potency THC marijuana from the perspective of an addiction psychiatrist. The Journal of the Missouri State Medical Association, 115(6).

Substance Abuse and Mental Health Services Administration (2019a). Key substance use and mental health indicators in the United States: Results from the 2018 national survey on drug use and health. https://www.samhsa.gov/data/release/2018-national-survey-drug-useand-health-nsduh-releases.

Substance Abuse and Mental Health Services Administration. (2019). Know the risks of marijuana. SAMHSA. http://www.samhsa.gov/marijuana.

Sullivan, E., \& Austriaco, N. (2016). A virtue analysis of recreational marijuana use. The Linacre Quarterly, 83(2), 19-28.

Van Rijnsoever F. J. (2017). (I can't get no) Saturation: A simulation and guidelines for sample sizes in qualitative research. PloS one, 12(7),44-71 e0181689. https://doi.org/10.1371/journal.pone.0181689.

Vass, C., Rigby, D., \& Payne, K. (2017). The role of qualitative research methods in discrete choice experiments. Medical decision making : an international journal of the Society for Medical Decision Making, 37(3), 298-313. https://doi.org/10.1177/0272989X16683934.

Vendel, E., Rottschäfer, V., \& de Lange, E. (2020). The 3D brain unit network model to study spatial brain drug exposure under healthy and pathological conditions. Pharmaceutical Research, 37(7), 137. https://doi.org/10.1007/s11095-020-2760-y.

Volkow, N. D., Baler, R. D., Compton, W. M., \& Weiss, S. R. (2014). Adverse health effects of marijuana use. New England Journal of Medicine, 370(23), 22192227. https://doi.org/10.1056/nejmra1402309.

Volkow, N. D., Koob, G. F., McLellan, A.T. (2016). Neurobiological advances from the brain disease model of addiction. New England Journal of Medicine, 374(4), 363-371. doi:10.1056/NEJMra1511480.

Wendt, D. C., \& Gone, J. P. (2017). Group therapy for substance use disorders: A survey of clinician practices. Journal of Groups in Addiction \& Recovery, 12(4), 243-259. https://doi.org/10.1080/1556035X.2017.1348280.

Xu, B., \& LaBar, K. S. (2019). Advances in understanding addiction treatment and recovery. Science Advances, 5(10), 1-14. doi: 10.1126/sciadv.aaz6596.

Zvonarev, V., Fatuki, T. A., \& Tregubenko, P. (2019). The public health concerns of marijuana legalization: An overview of current trends. Cureus, 11(9), 53-59. doi: 10.7759/cureus.5806. 


\section{Notes on Contributors}

Darlene Walker, PsyD, MFT, is a clinical mental health professional in the state of California working with patients addressing substance abuse disorders.

Casey Mace Firebaugh, $\mathrm{PhD}, \mathrm{MPH}$, is a professor of public health at Central Washington University and an Associate Scientist at the Oregon Research Institute. Dr. Mace Firebaugh publishes research in environmental, mental, and public health. ORCID ID: 0000-0001-8015-0022

Gina Craft, PsyD, MS, MA, is a mental health professional and adjunct faculty at University of Phoenix, School of Behavioral and Social Sciences. Dr. Craft also

Patrick McKiernan, $\mathrm{PhD}, \mathrm{LCAD}$, is a mental health professional residing in the state of Kentucky, who specializes in additiction treatment and therapy. Dr. McKiernan is a professor in the School of Behavioral Sciences at California Southern University.

Cynthia Palmisano, PsyD, is a core faculty in the clinical psychology program at Saybrook University who specializes in forensic psychology.

\section{Declarations}

- Ethics approval and consent to participate - This study was approved by the California Southern IRB (2020).

- Consent for publication - Participant consent included dissemination of results.

- Availability of data and materials - The data is not publicly available due to low sample size and qualitative nature. However, requests to corresponding author for data can be made and subject to further IRB approval may be available.

- Competing interests - Authors declare no competing interests

- Funding - Authors declare no funding

- Authors' contributions - DW was the study lead, CMF oversaw methodology, PM, CP, $\mathrm{CMF}$, and DW contributed to thematic analysis, writing of manuscript, GC participating in writing of manuscript and editing revisions of the manuscript.

\section{Appendix A}

The instrument used for this study consisted of 20 interview questions, including:

1. Prior to legislative changes, what percentage of your clients used marijuana daily or suffered from SUD or CUD?

2. In your experience working with clients diagnosed with CUD, has legalization affected your approach when treating this disorder?

3. In what ways has the legalization of marijuana affected your clients' use behaviors?

4. How do you feel about clients using marijuana daily? Would you feel differently if they were drinking alcohol daily?

5. In what ways has the legalization of marijuana changed how your clients who use marijuana present in therapy?

6. In what ways does the method of marijuana ingestion used by your clients affect your attitudes toward treatment?

7. In what ways has increased access to marijuana affected your clients' use behaviors?

8. How do your clients express their marijuana use in therapy; has their expression changed since legalization? 
9. Has the legalization of marijuana altered use behaviors among your clients who began using marijuana prior to legislative changes?

10. What do your clients say are their primary influences and attitudes toward marijuana use when they began using marijuana?

11. How has the legalization of marijuana influenced your clients' views and use behaviors related to marijuana?

12. Thinking of your personal experience, have you felt a change in societal views of marijuana use since legalization?

13. Since legalization, how many of your clients grow cannabis products, purchase them from a storefront or dispensary, or acquire marijuana by some other means?

14. What patterns of use differences are there between your clients who have used marijuana since adolescence and those who began using it post-legislation as an adult?

15. What would you like your clients who are using marijuana to know about potency and the different products available, i.e., edibles, tinctures, etc.?

16. Since legalization, what do your clients say are the positives and negatives associated with using marijuana?

17. Have your clients experienced negative consequences from marijuana use such as unemployment, legal difficulties, poor health, relationship issues, or other problems?

18. What information would be helpful to anyone considering using marijuana?

19. What would you tell young adults between the ages of 18 and 35 about starting or continuing the use of marijuana?

20. What, if any, are the unexpected outcomes from marijuana use people might not anticipate?

Manuscript received October 3, 2021

Final revision received December 11, 2021

Accepted December 22, 2021 